\title{
Efeitos de Níveis Crescentes de Fibra em Detergente Neutro na Dieta sobre a Digestão Ruminal em Bubalinos e Bovinos ${ }^{1}$
}

\author{
Nedilse Helena de Souza², Raul Franzolin³ ${ }^{3}$ Paulo Henrique Mazza Rodrigues ${ }^{4}$, \\ Gustavo Ribeiro Del Claro ${ }^{5}$
}

\begin{abstract}
RESUMO - Quatro bubalinos e quatro bovinos adultos com fístulas ruminais foram utilizados com o objetivo de se estudar os efeitos de diferentes níveis de fibra em detergente neutro na dieta sobre as características digestão ruminal. Foram avaliadas as degradabilidades da matéria seca, fibra em detergente neutro do feno de coastcross e do farelo de trigo, matéria seca do milho em grãos moídos e do farelo de soja; digestibilidade com indicador $\left(\mathrm{Cr}_{2} \mathrm{O}_{3}\right)$. Os animais foram delineados em dois quadrados latinos $(4 \mathrm{x} 4)$ com arranjo fatorial 4x2, sendo quatro níveis crescentes de FDN na MS (54, 60, 66 e 72\%) e duas espécies (bubalinos e bovinos). Cada subperíodo compreendeu 29 dias, sendo 13 de adaptação. Os bubalinos apresentaram maior desaparecimento ruminal da MS e FDN do feno de coastcross e da MS do farelo de soja que os bovinos, na maioria dos tempos de incubação. Por outro lado, o desaparecimento ruminal da FDN do farelo de trigo foi maior para os bovinos, somente nas primeiras horas. Para o coeficiente de digestibilidade da MS, houve interação de espécies com níveis de FDN. O coeficiente de digestibilidade da FDN foi influenciado pelos níveis de FDN e, para o coeficiente de digestibilidade da PB, não foram notados efeitos de espécies ou níveis de FDN.
\end{abstract}

Palavras-chave: bubalino, bovino, degradabilidade ruminal, digestão, fibra em detergente neutro

\section{Effects of the Increasing Levels of Neutral Detergent Fiber in the Diet on the Digestion in Water Buffaloes and Cattle}

\begin{abstract}
Four buffaloes and four cattle rumen fistulated were used with the objective to study the effects of different levels of neutral detergent fiber in the diet on the digestion characteristics. The In situ degradations of dry matter (DM), neutral detergent fiber (NDF) of the coastcross hay and wheat meal, DM of the corn ground and soybean meal were evaluated. The digestibilities of DM, crude protein and NDF of the diets were also evaluated using a $\mathrm{Cr}_{2} \mathrm{O}_{3}$ as a marker. The animals were allotted to two in a $4 \mathrm{x} 2$ factorial arrangement with four increasing levels of NDF in the DM (54, 60,66 and 72\%) and two animal species (buffaloes and cattle). Four twenty-nine days subperiods were used, with 13 days for diet adaptation. The buffaloes showed higher ruminal DM and NDF disappearance of the Coast-cross hay and soybean meal DM than cattle, in most of the incubation times. On the other hand, the ruminal NDF disappearance of wheat meal was higher for the cattle only in the first hours. There was interaction between species and NDF levels for the DM digestibility coefficients. The NDF levels influenced the NDF digestibility coefficient and it was not noticed effects of species or NDF levels for the CP digestibility coefficient.
\end{abstract}

Key Words: buffalo, cattle, digestion, neutral detergent fiber, ruminal degradability

\section{Introdução}

A fibra e a proteína consumidas pelos ruminantes, obtidas de diferentes fontes e variadas composições, têm influência na atividade microbiana no rúmen. Há indícios de que forragens de baixa qualidade são melhores aproveitadas pelos bubalinos que pelos bovinos (RAZDAN et al., 1971; NOGUEIRA FILHO, 1995).

A degradabilidade das frações fibrosas de alimentos volumosos cresce com o aumento da proporção de volumoso na dieta (CHIMWANO et al.,
1976). HOPSON et al. (1963) demonstraram que a degradabilidade da celulose varia muito nas primeiras 24 horas de incubação e é aumentada com o uso de alfafa, como parte da ração. KENNEDY e BUNTING (1992), trabalhando com diferentes proporções de volumosos $(90,60$ e $30 \%)$, em carneiros fistulados, observaram diminuição linear da degradabilidade da fração FDN do feno, com a redução da quantidade de volumosos da dieta.

MERTENS (1992) e RESENDE et al. (1995) observaram que a fibra em detergente neutro (FDN) é o melhor indicador para a estimativa do potencial de

\footnotetext{
1 Parte da tese de Mestrado do primeiro autor - projeto financiado pela FAPESP.

2 Estudante de Mestrado em Qualidade e Produtividade Animal - FZEA/USP. E.mail: nhs@netsite.com.br

3 Professor Associado do Departamento de Zootecnia - FZEA/USP. E.mail: rfranzol@usp.br

4 Professor Assistente do Departamento de Nutrição e Produção Animal - FMVZ/USP. E.mail: pmazza@usp.br

5 Estudante de Graduação em Zootecnia - FZEA/USP - Bolsista de IC - PIBIC/USP/CNPq.
} 
consumo dos alimentos pelos ruminantes que a fibra bruta (FB) ou fibra em detergente ácido (FDA).

DEVENDRA (1983), em revisão sobre a capacidade de utilização de nutrientes (matéria seca, fibra bruta, proteína bruta e balanço de nitrogênio) oriundos da digestão de volumoso e palhas por bubalinos e zebuínos, observou melhor desempenho dos bubalinos, comparados aos bovinos, quanto à digestibilidade da fração fibrosa e maior retenção de nitrogênio, principalmente quando as dietas eram pobres em proteínas.

Alguns trabalhos comparativos envolvendo taurinos, zebuínos e bubalinos vêm sendo realizados no Brasil, visando detectar diferenças quanto à capacidade de ingestão e utilização dos alimentos. GARCIA (1982), ao estudar a digestibilidade da MS em quatro grupos genéticos de novilhos (Holandês, 1/2 Holandês x zebuíno e bubalinos) submetidos a consumo de $90 \mathrm{~g} \mathrm{MS} / \mathrm{kg}^{0,75}$, constatou que a digestão total da MS não diferiu entre os grupos de animais, quando trabalhou com uma ração contendo $40 \%$ de concentrados. Entretanto, quando os animais receberam uma ração com $60 \%$ de concentrados, a digestão total foi maior para os holandeses e não diferiu entre os demais grupos. Além disso, concluiu que apenas a digestão da celulose no rúmen apresentou variação significativa, tendo os bubalinos apresentado menores índices de digestibilidade que os demais grupos genéticos, que não diferiram entre si.

RODRIGUES et al. (1996) não verificaram diferenças estatísticas no consumo de matéria seca entre bubalinos e bovinos (Nelores e holandeses) alimentados com rações contendo diferentes níveis de FDN. Porém, apesar de os parâmetros ruminais não terem sido avaliados, os búfalos apresentaram os menores valores de ingestão e digestibilidade dos nutrientes.

A eficiência quanto ao aproveitamento dos nutrientes e o potencial de consumo ainda não estão esclarecidos, havendo necessidade de estudos adicionais.

Neste sentido, o objetivo do trabalho foi verificar os efeitos da inclusão de quatro níveis crescentes de FDN na dieta em duas espécies de ruminantes domésticos (bubalinos e bovinos) e as possíveis relações interespecíficas sobre as degradabilidades ruminais da matéria seca (MS) e fibra em detergente neutro (FDN) dos ingredientes da ração e a digestibilidade com marcador.

\section{Material e Métodos}

O experimento foi realizado na Faculdade de Zootecnia e Engenharia de Alimentos, localizada no Campus de Pirassununga da USP. Foram utilizados quatro bubalinos da raça Mediterrâneo e quatro bovinos da raça Holandês, castrados, com peso vivo médio inicial de 580 e $410 \mathrm{~kg}$, respectivamente, todos fistulados no rúmen com cânulas de látex de $10 \mathrm{~cm}$ de diâmetro. Antes do início do experimento, os animais receberam suplementação de complexo vitamínico A, D e E, por meio de injeção intramuscular, e foram tratados com vermífugo, vacinados contra febre aftosa.

O experimento teve quatro subperíodos de 29 dias cada, sendo 13 dias de adaptação dos animais à dieta.

A ingestão média de MS diária calculada foi de 60 e e $77 \mathrm{~g} / \mathrm{kg}^{0,75}$, para os bubalinos para os bovinos, respectivamente.

A quantidade total diária de alimentos foi fornecida em duas refeições, metade no período da manhã $(8 \mathrm{~h})$ e a outra no período da tarde $(16 \mathrm{~h})$. Uma mistura de sal mineral foi fornecida ad libitum no período da manhã, antes da alimentação.

Quatro dietas foram formuladas para serem isoprotéicas e conterem quatro níveis crescentes de FDN (54, 60, 66 e 72\% na MS). O concentrado foi constituído de milho em grãos moídos, farelo de soja, farelo de trigo, óleo de soja e uréia. O único volumoso utilizado foi o feno de coastcross (Cynodon dactylon), o qual teve os fardos desintegrados, resultando em fragmentos de aproximadamente $10 \mathrm{~cm} \mathrm{de}$ comprimento. A quantidade de ração fornecida foi calculada em função do consumo durante o período de adaptação, para que não existissem sobras. Amostras dos ingredientes das rações (menos o óleo de soja e a uréia) foram realizadas semanalmente, durante todo o período experimental e analisadas no laboratório, para a determinação da MS, PB e FDN.

Na Tabela 1, encontram-se a composição das rações e as análises realizados dos ingredientes utilizados.

As degradabilidades da MS e FDN do feno de coastcross e do farelo de trigo e a MS do milho em grãos moídos e do farelo de soja foram determinadas durante a última semana de cada período.

Os procedimentos para o desenvolvimento da técnica in situ de sacos de náilon foram realizados conforme ØRSKOV et al. (1980) e HUNTINGTON 
Rev. bras. zootec.

Tabela 1 - Composição das rações e teores de matéria seca, proteína e fibra em detergente neutro das rações e dos ingredientes

Table 1 - Composition of the diets and contents of dry matter, crude protein and neutral detergent fiber of the diets and of ingredients

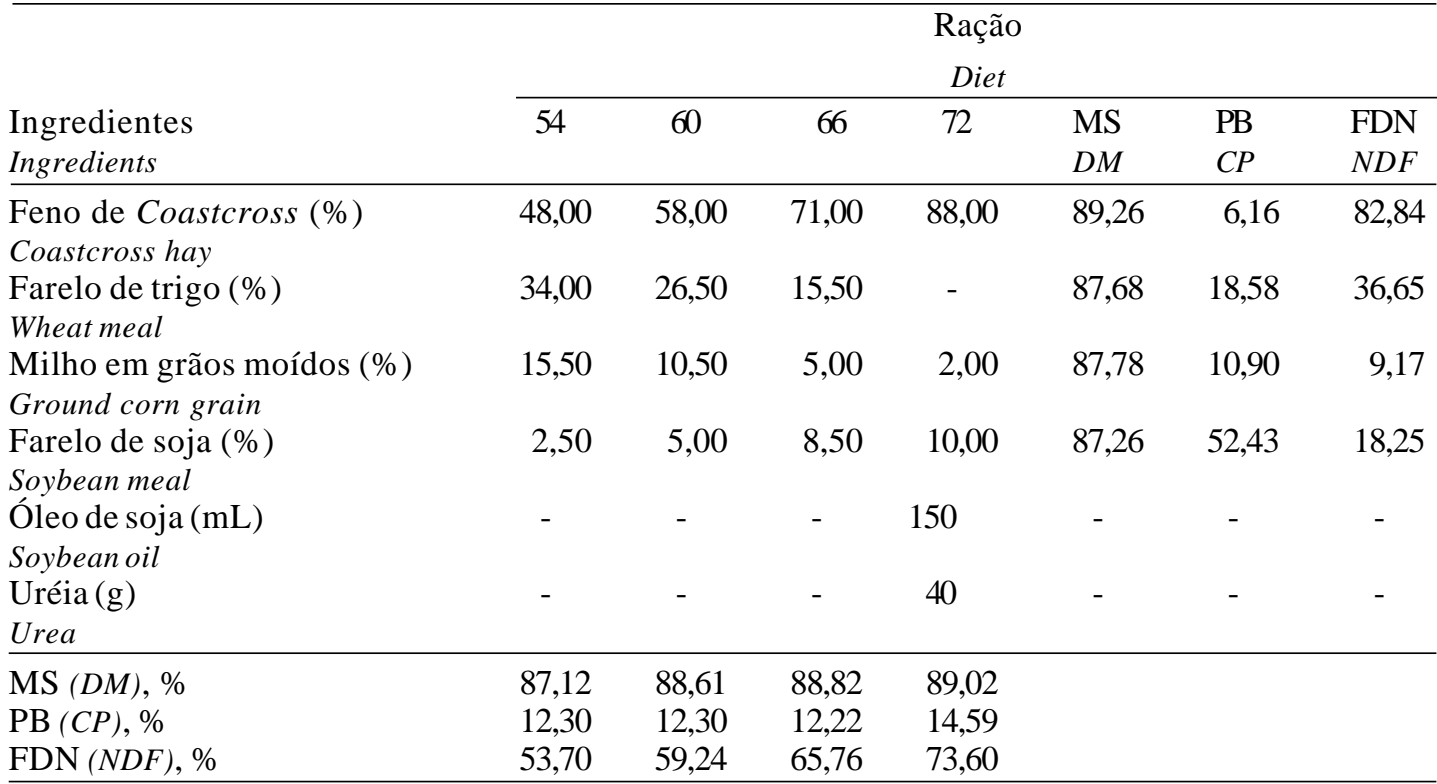

e GIVENS (1995). Foram utilizados sacos de náilon com $11 \times 23,5 \mathrm{~cm}$ e abertura de poros média de $53 \mu \mathrm{m}$. $\left(\mathrm{ANKON}{ }^{\circledR}\right.$, INC.). Cerca de $7 \mathrm{~g}$ de MS de cada ingrediente, moídos em peneira de $2 \mathrm{~mm}$, foram colocados em cada saquinho. Para determinações das curvas de desaparecimento da MS dos concentrados, milho em grãos moídos e farelo de soja, 10 saquinhos $(2 \times 5=$ ingrediente $\mathrm{x}$ tempo de incubação) foram colocados no rúmen de cada animal dentro de uma sacola de náilon com zíper na parte superior (30 $\mathrm{cm}$ de largura e $40 \mathrm{~cm}$ de altura). As sacolas foram amarradas com fios de náilon de aproximadamente $50 \mathrm{~cm}$ e com pesos na parte inferior para sua colocação no rúmen e melhor posicionamento. Os saquinhos foram incubados nos tempos $48,24,12,6$ e 3 horas e retirados todos juntos em cada período. Com o feno e farelo de trigo foram introduzidos no rúmen de cada animal 14 saquinhos $(2 \times 7=$ ingredientes $\mathrm{x}$ tempo) e retirados todos juntos dentro das sacolas, nos tempos 96, 72, 48, 24, 12, 6 e 3 horas. Após a retirada das sacolas do rúmen, estas foram lavadas todas ao mesmo tempo, dentro de baldes com água em temperatura ambiente, e os saquinhos, retirados das sacolas, lavados até que a água no balde estivesse transparente e secos em estufa de ventilação forçada a $65^{\circ} \mathrm{C}$ por 72 horas. Posteriormente, foram pesados e submetidos a análises bromatológicas.

Os teores de MS, PB e FDN foram determinados conforme técnicas descritas por SILVA (1981).

A digestibilidade pelo uso de indicador foi determinada com a introdução no rúmen de $15 \mathrm{~g}$ de óxido de crômio, dividido em duas vezes ao dia, do 14 a ao $22^{\circ}$ dia, e as amostragens de fezes de cada período foram feitas diariamente no período da manhã (entre $7 \mathrm{~h} 30$ e $8 \mathrm{~h}$ ) e da tarde (entre $3 \mathrm{~h} 30$ e $4 \mathrm{~h}$ ), do $19^{\circ}$ ao 23 o dia. As fezes foram retiradas diretamente do reto do animal e acondicionadas em um único saco plástico por período, em porções aproximadas de $150 \mathrm{~g}$ por coleta, as quais foram imediatamente armazenadas em congelador a $-10^{\circ} \mathrm{C}$, conforme SILVA et al. (1968).

As dosagens de cromo foram feitas no mesmo espectrofotômetro da análise de amônia, em comprimento de ondas de $500 \mathrm{~nm}$, seguindo-se metodologia colorimétrica da S-difenilcarbazida, conforme técnica descrita por GRANER (1972).

Foi utilizado o delineamento experimental em dois quadrados latinos 4 x 4 (PIMENTEL GOMES, 1985) com um arranjo fatorial de tratamentos do tipo 4 x 2, correspondendo aos níveis de FDN (54, 60, 66 e $72 \%$ na MS) e às espécies (bubalina e bovina).

Os dados obtidos foram analisados por meio do programa computacional Statistical Analysis System (SAS Institute Inc., 1985). As análises referentes ao desaparecimento dos alimentos, em cada tempo de incubação, e os respectivos parâmetros da degradabilidade, separaram como fontes de variação os 
efeitos dos níveis de FDN (N), as espécies (E), a interação entre esses fatores ( $\mathrm{E} \times \mathrm{N}) \mathrm{e}$, ainda, as linhas (subperíodos) e as colunas (animais). Quando a interação entre os fatores níveis de FDN e a espécie foi significativa $(\mathrm{P}<0,05)$, foram testados os efeitos dos níveis de FDN dentro das espécies e vice-versa, por meio do uso de contrastes ortogonais. Quando estas não foram significativas, utilizou-se a probabilidade dos efeitos principais.

\section{Resultados e Discussão}

Constam das Tabelas 2, 3, 4 e 5 os dados da degradabilidade da MS do feno de coastcross, do farelo de trigo, do milho em grãos moídos e do farelo de soja.

$\mathrm{O}$ efeito da espécie no desaparecimento ruminal da MS do feno de coastcross foi significativo $(\mathrm{P}<0,05)$ nos tempos de 3, 6, 24, 48 e 72 horas, observando-se maior desaparecimento da MS dos bubalinos de 3,90 a $16,12 \%$ sobre os bovinos.

NOGUEIRA FILHO (1995) verificou que, para a degradabilidade potencial da MS do feno de capim de coastcross, houve diferenças significativas entre bubalinos e zebuínos e espécie, em função de tempo ( $\mathrm{P}<0,05$ ), com valor médio de 66,12 ee $60,58 \%$, para os búfalos e Nelores, respectivamente. No presente experimento, não se observou ( $\mathrm{P}>0,05)$, entre espécies, degradabilidade potencial da MS do feno.

O efeito da espécie foi significativo $(\mathrm{P}<0,05)$ para a degradabilidade efetiva para qualquer das taxas de passagem utilizadas da MS do feno, com valores mais elevados em bubalinos.

Houve efeito significativo $(\mathrm{P}<0,05)$ dos níveis de FDN sobre o desaparecimento ruminal da MS do farelo de trigo, nos tempos de 3 e 24 horas, e para a constante $b$ (fração potencialmente degradável), apresentando resposta linear; no tempo 48 horas, ocorreu desvio do modelo quadrático. VALADARES FILHO (1994) apresentou dados da degradabilidade in situ efetiva, com taxa de passagem de $0,02 / \mathrm{h}$ para MS do farelo de trigo variando de 66,50 a $74,50 \%$, sendo a média geral do experimento de $74,84 \%$.

A influência das espécies sobre o desaparecimento ruminal da MS do milho em grãos moídos ocorreu significativamente nos tempos de 3 e 12 horas e para as degradabilidades efetivas, com taxas de passagem de 0,02 e $0,04 / \mathrm{h}$; os bubalinos apresentaram valores mais elevados que os bovinos, 10,$54 ; 12,43 ; 4,69$; e 7,04\%, respectivamente. Para os níveis de FDN, houve efeito sobre os tempos de 24 e 48 horas, a constante $b$, a degradabilidade potencial $(a+b)$ e, também, as degradabilidades efetivas, com taxas de passagem de 0,02 e $0,04 / \mathrm{h}$, havendo sempre um desvio do modelo quadrático para as variáveis.

O efeito da espécie no desaparecimento ruminal da MS do farelo de soja foi significativo $(\mathrm{P}<0,05)$ nos tempos de 6, 12 e 24 horas, observando-se taxa de desaparecimento da MS dos bubalinos, de 6,30 a $15,48 \%$, maior que a dos bovinos. A taxa de degradação $c$ e a degradabilidade efetiva com taxas de passagens de 0,02 e $0,04 / \mathrm{h}$, nos bubalinos, foram mais elevados que nos bovinos de 33,72; 3,69; e 6,91\%, respectivamente. Houve efeito significativo $(\mathrm{P}<0,05)$ para a interação $\mathrm{E}$ x N no tempo de 3 horas e na fração potencialmente degradável $b$.

VALADARES FILHO (1994) verificou que, para taxa de passagem de $0,02 / \mathrm{h}$, a degradabilidade efetiva da MS do farelo de soja variou de 80,90 a $84,40 \%$. No presente experimento, como houve diferenças significativas $(\mathrm{P}<0,01)$ para as espécies, a média dos bovinos foi de $84,07 \%$ e a dos bubalinos, $87,29 \%$, portanto, os bubalinos apresentaram média mais elevada que os dados observados na literatura.

A equação da reta obtida no tempo 3 horas para os bubalinos foi:

$$
\mathrm{Y}=41,74+0,02 \mathrm{X}
$$

em que $\mathrm{Y}$ é desaparecimento da MS do farelo de soja (\%) e X, o nível de FDN (\% MS).

Não foi possível obter uma equação da reta para os bovinos, por ser uma constante.

A equaçãodareta da fração potencialmente degradável $b$ para os bubalinos foi: $\mathrm{Y}=113,73-0,69 \mathrm{X}$ e a dos bovinos, $\mathrm{Y}=-4.592,82+227,80 \mathrm{X}-3,67 \mathrm{X}^{2}+0,02 / \mathrm{hX} \mathrm{X}^{3}$, em que $\mathrm{Y}$ é a fração potencialmente degradável do farelo de soja (\%) e X, o nível de FDN (\% MS).

Os níveis de FDN afetaram linearmente os tempós 6 e 12 horas, a degradabilidade potencial e a degradabilidade efetiva da MS do farelo de soja para taxa de passagem $0,04 / \mathrm{h}$. Foi observada uma equação linear para a degradabilidade efetiva com taxa de passagem 0,04/h:

$$
\mathrm{Y}=64,04+0,18 \mathrm{X}
$$

em que Y é a degradação efetiva (\%) e X, o nível de FDN (\% MS).

Nas Tabelas 6 e 7, encontram-se os dados da degradabilidade da FDN do feno de coastcross e do farelo de trigo.

O efeito da espécie em alterar o desaparecimento ruminal da FDN do feno de coastcross foi significa- 
Rev. bras. zootec.

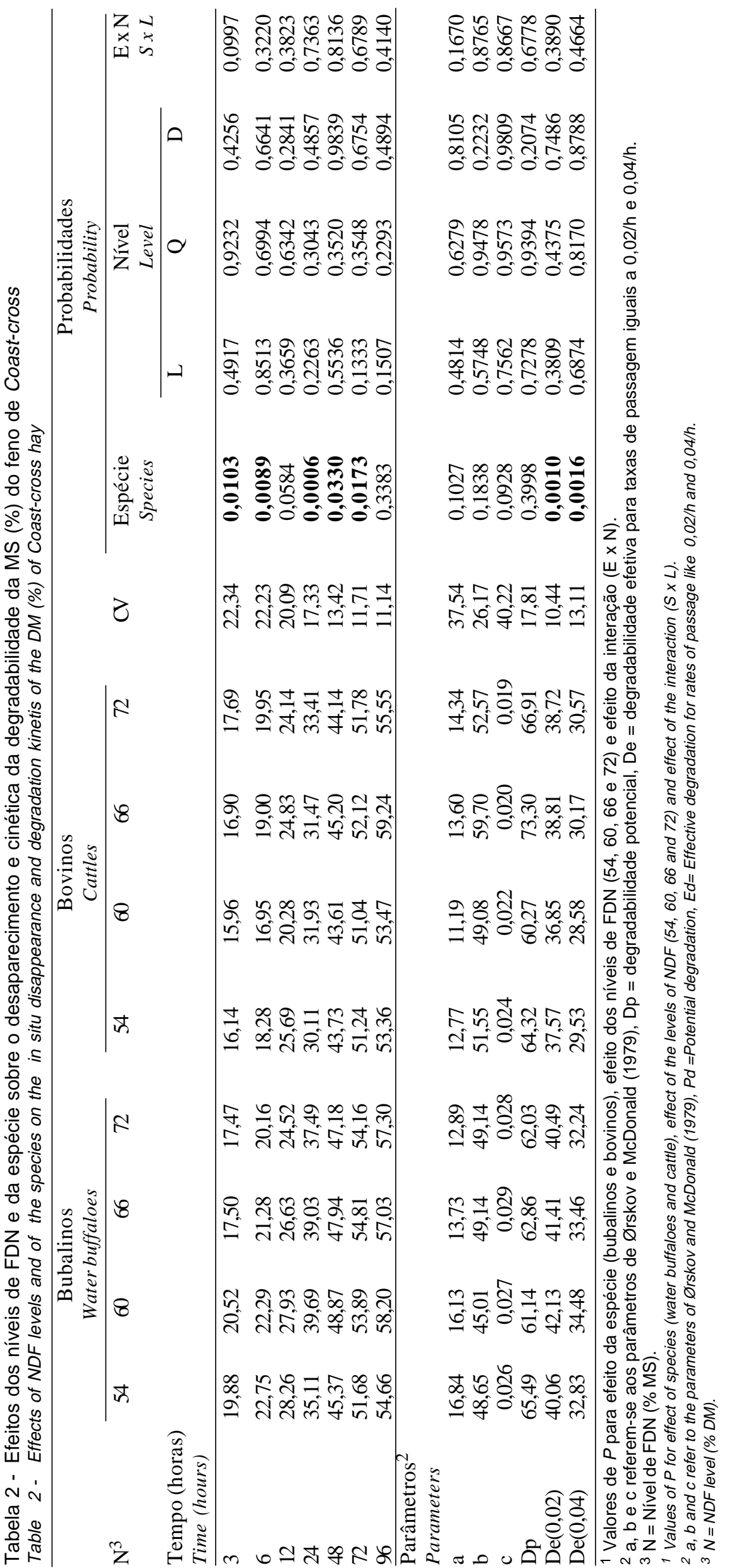


SOUZA et al.




Rev. bras. zootec.

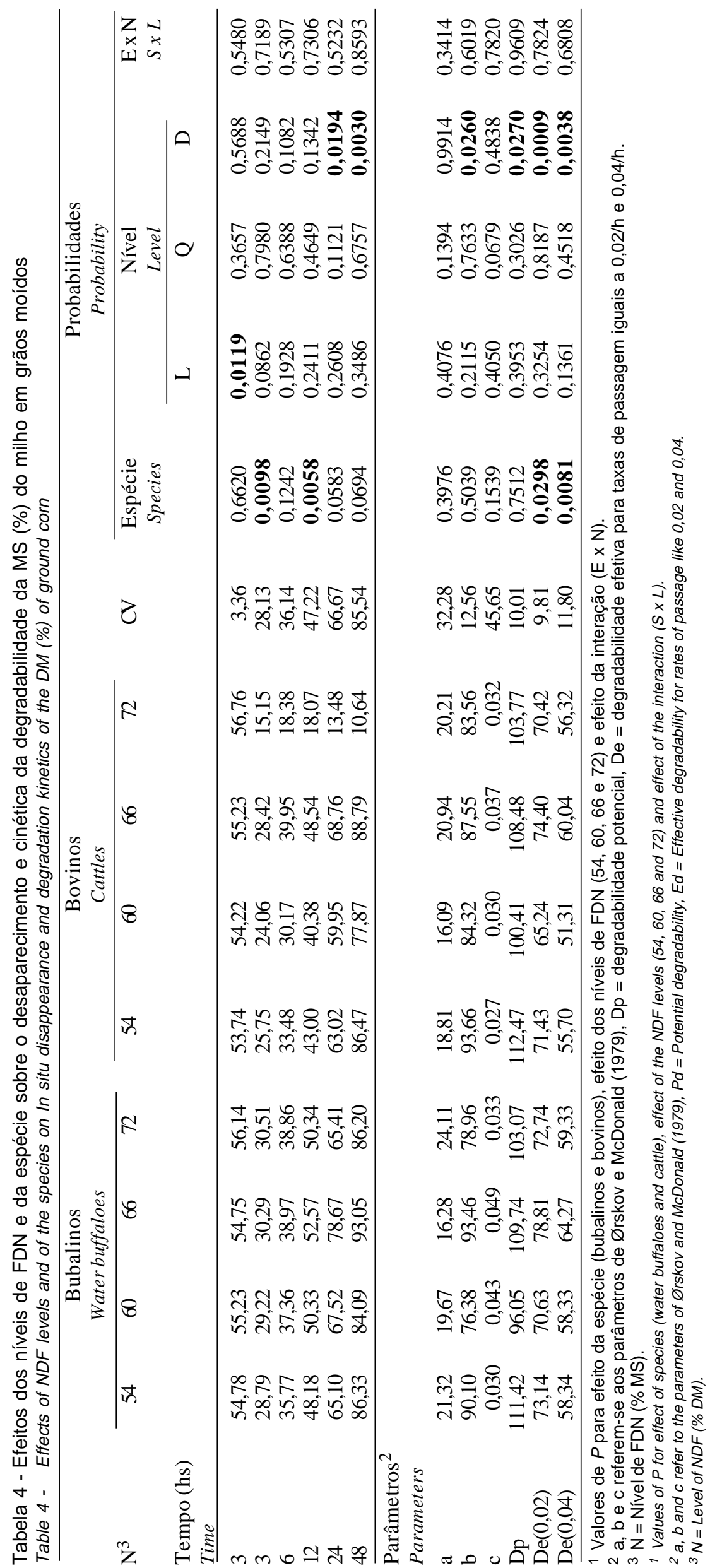


SOUZA et al.

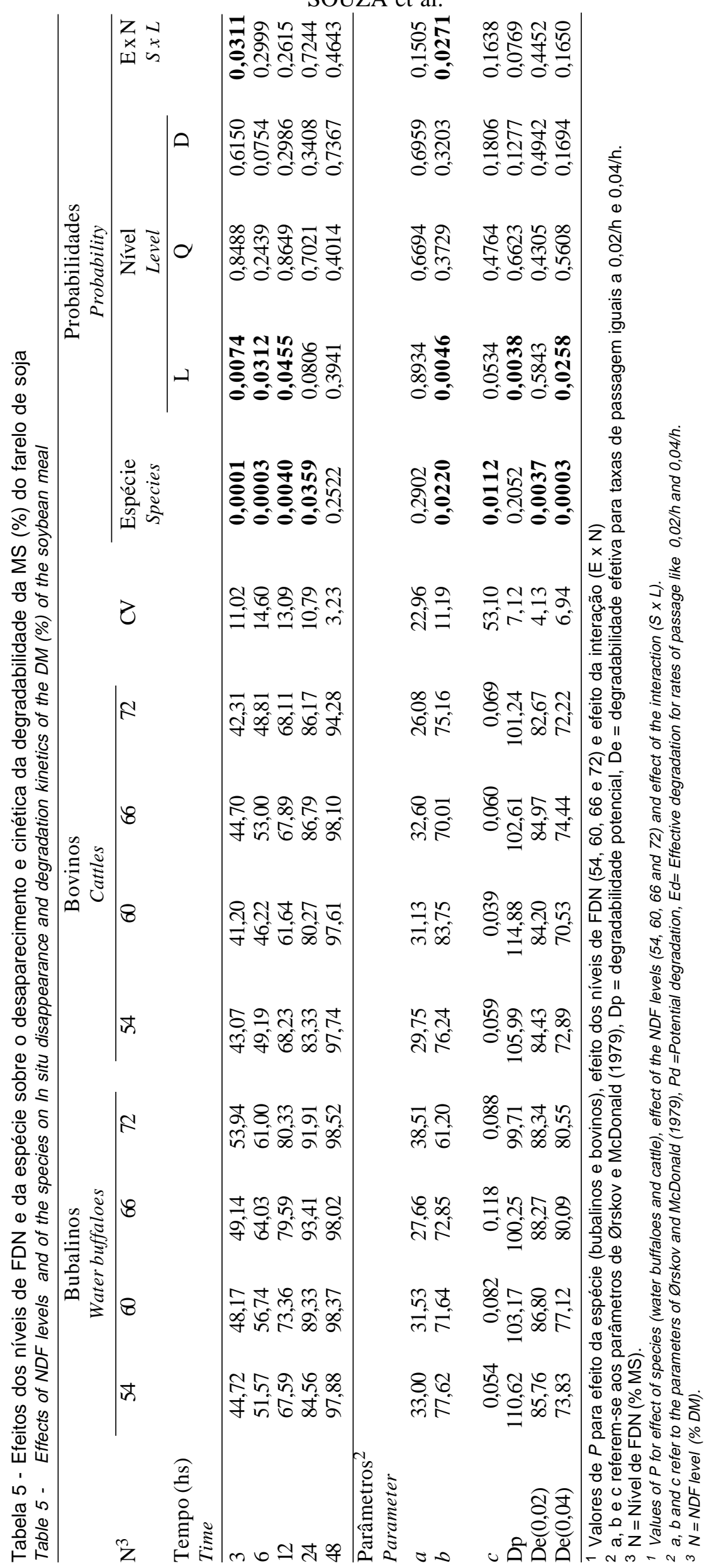


tivo $(\mathrm{P}<0,05)$ nos tempos de 3, 6, 24, 48 e 72 horas, observando-se elevação no desaparecimento da FDN dos bubalinos de 5,00 a 30,83\% sobre os bovinos. $\mathrm{O}$ efeito da espécie também foi significativo $(\mathrm{P}<0,05)$ para a degradabilidade efetiva, para qualquer taxa de passagem utilizada para a FDN do feno, com valores maiores em bubalinos.

Houve marcante diferença entre os resultados deste trabalho quanto à degradabilidade da FDN e aqueles de NOGUEIRA FILHO (1995), que não detectou diferença entre espécies animais $(\mathrm{P}>0,05)$. Apesar disso, o autor afirma que, em alguns momentos da prova de degradação, houve tendência dos bubalinos a aproveitarem melhor a fração FDN do feno que os Nelores.

O efeito dos níveis de FDN foram significativos $(\mathrm{P}<0,01)$ para o desaparecimento ruminal da FDN do farelo de trigo, sendo que, no tempo de 48 horas, ocorreram desvio da equação quadrática e resposta curvilinear para o parâmetro $a$.

Observou-se o efeito da espécie sobre o desaparecimento ruminal da FDN do farelo de trigo nos tempos de 3 e 12 horas, com aumento de 36,04 e $14,73 \%$, respectivamente, para os bovinos em relação aos bubalinos. O mesmo fato ocorreu com a constante $a$ (fração rapidamente degradável) e para as degradabilidades efetivas com taxas de passagem de 0,02 e $0,04 / \mathrm{h}$, sendo os valores mais altos de 37,86 ; 6,76 ; e $8,89 \%$, respectivamente.

RODRIGUES (1996) afirmou que, das constantes utilizadas (iguais ao do presente experimento), as taxas de degradação de FDN ou FDA (constante $c$ ) apresentaram coeficientes de variação bastante altos (24\%), quando comparadas aos outros parâmetros, o que também ocorreu no presente experimento. Este fato restringe sua utilização como indicador dos resultados obtidos sobre a degradabilidade da fibra.

Os resultados apresentados na Tabela 8 mostra os coeficientes de digestibilidade da matéria seca (CDMS), coeficiente de digestibilidade da fibra em detergente neutro (CDFDN) e coeficiente de digestibilidade da proteína (CDPB) para as duas espécies e os quatro níveis de FDN na ração.

Ocorreu interação (E x N) no CDMS, resultando em uma equação linear para a espécie bovina, sendo esta igual a:

$$
\mathrm{Y}=93,95-0,55 \mathrm{X}
$$

em que Y é CDMS (\%) e X, o nível de FDN (\%MS).

Não foi possível obter a equação da reta para os bubalinos, por ser uma constante.

A média observada para o CDMS no nível 53\% de FDN dos bovinos $(65,02 \%)$ foi $4,89 \%$ maior que a dos bubalinos $(62,01 \%)$. Ocorreu semelhança entre espécies no nível 59\% de FDN. Já a partir dos níveis de 66 e $73 \%$ de FDN, houve elevação do CDMS nos bubalinos de 1,45 e $16,20 \%$, respectivamente, em relação aos bovinos.

Com os dados observados no experimento, não foi possível esclarecer a causa da digestibilidade constante da MS ocorrida nos bubalinos em relação aos níveis de FDN.

VALADARES FILHO et al. (1990) relataram que não houve diferença $(\mathrm{P}>0,05)$ entre grupos genéticos para as digestões total e parcial da MS com rações contendo $56 \%$ de volumoso, o que foi explicado como pela restrição alimentar. Em condições de alimentação ad libitum e com rações de boa qualidade, os taurinos geralmente apresentam maior consumo de MS que zebuínos e/ou bubalinos (GRANT et al.,1974; GONÇALVES, 1988) e, nestas condições, poderia haver maiores coeficientes de digestão total para os animais que consomem menos MS, conforme observado para búfalos (GRANT et al., 1974; BHATIA et al., 1979; VALADARES FILHO, 1985).

Em oposição, LORENZONI (1984) e GONÇALVES et al. (1991) verificaram que não houve diferença significativa $(\mathrm{P}>0,05)$ entre os grupos genéticos (Nelore, Holandês, Búfalo, 1/2 Holandês x zebuíno e 3/4 Holandês x zebuíno) dentro de cada ração para os dois níveis de consumo estudados, um ad libitum e

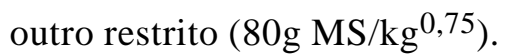

Os níveis de FDN influenciaram significativamente $(\mathrm{P}<0,01)$ o $\mathrm{CDFDN}$, apresentando resposta linear e corroborando os resultados de MILLER e MUNTIFERING (1985). Para este parâmetro, as espécies não apresentaram diferenças $(P>0,05)$, o que contrasta com os dados de DEVENDRA (1983), que observou maior digestibilidade da fração fibrosa pelos bubalinos em comparação aos bovinos.

Para CDPB, os níveis de FDN e as espécies não apresentaram diferenças significativas $(\mathrm{P}>0,05)$, dados que não diferem daqueles apresentados por SEBASTIAN et al. (1970), VIRK et al.(1981)e GOMES (1982), porém contradizem resultados de EZEQUIEL (1987), que detectou menor coeficiente de digestibilidade aparente da proteína bruta para os holandeses comparados aos Nelores, aos 1/2 Holandês x zebuíno e aos búfalos, em função da maior excreção de nitrogênio metabólico fecal, quando trabalhou com rações à base de feno de capim-gordura e raspa de mandioca com 3,37; 8,25; e $13,00 \%$ de PB na matéria seca da ração. 
SOUZA et al.

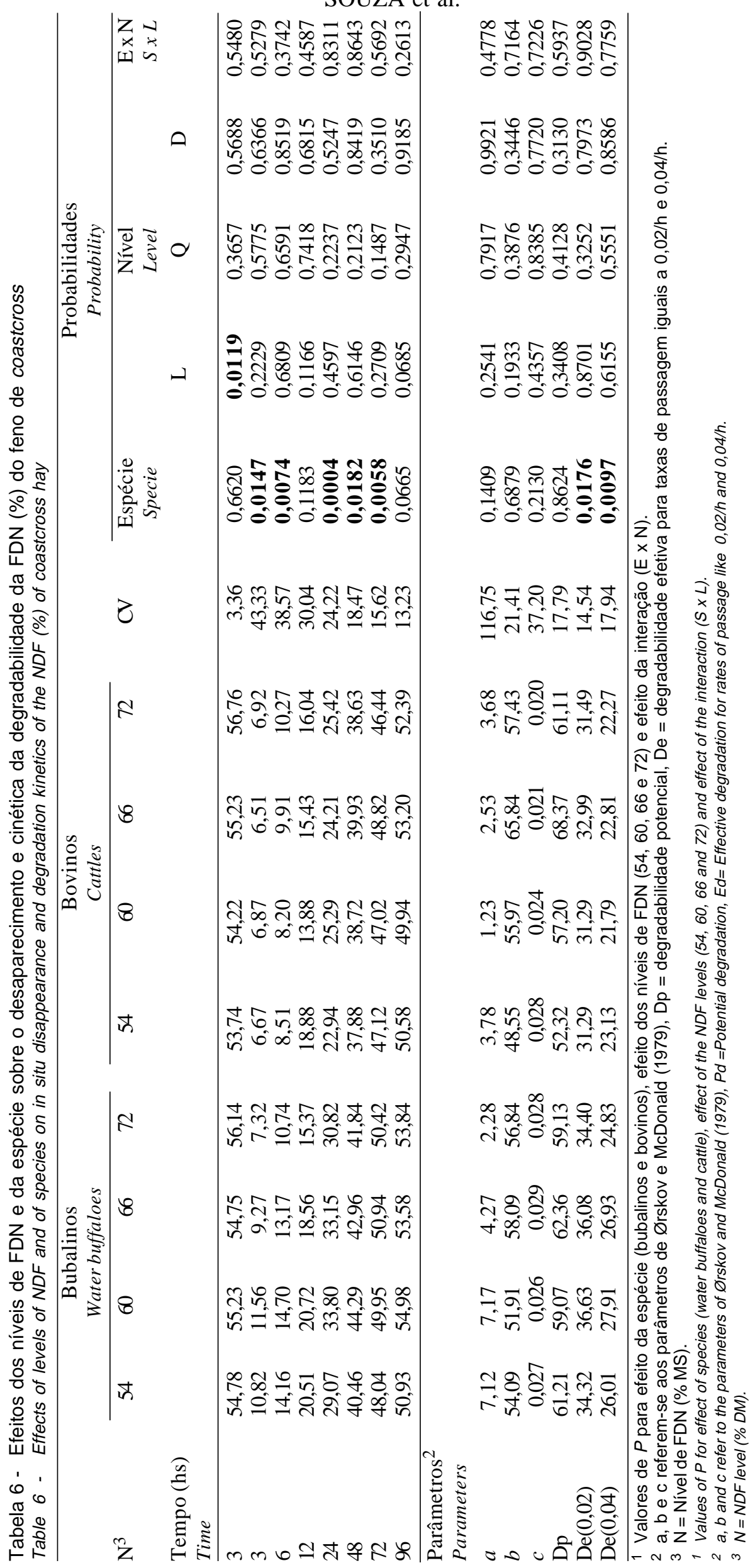


Rev. bras. zootec.

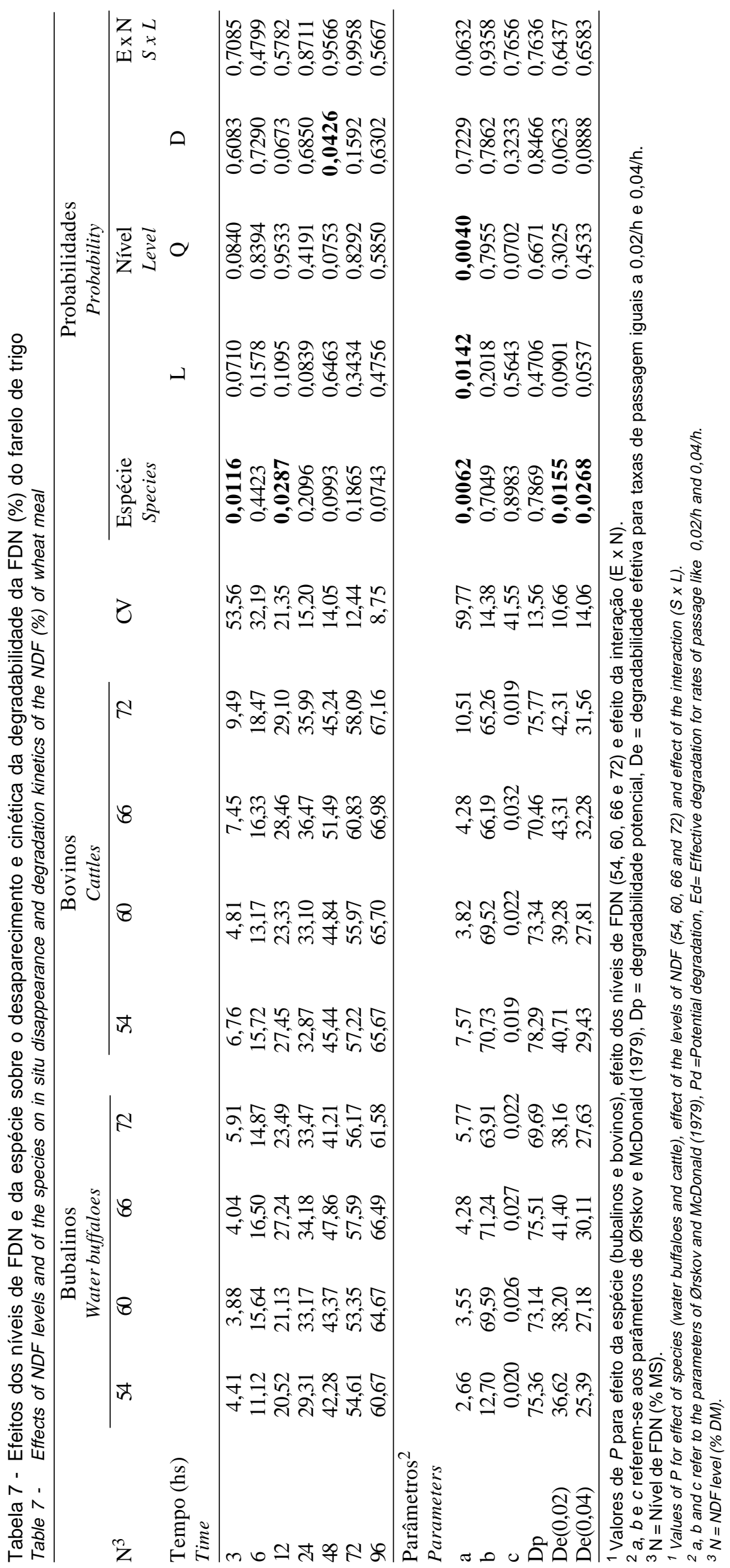




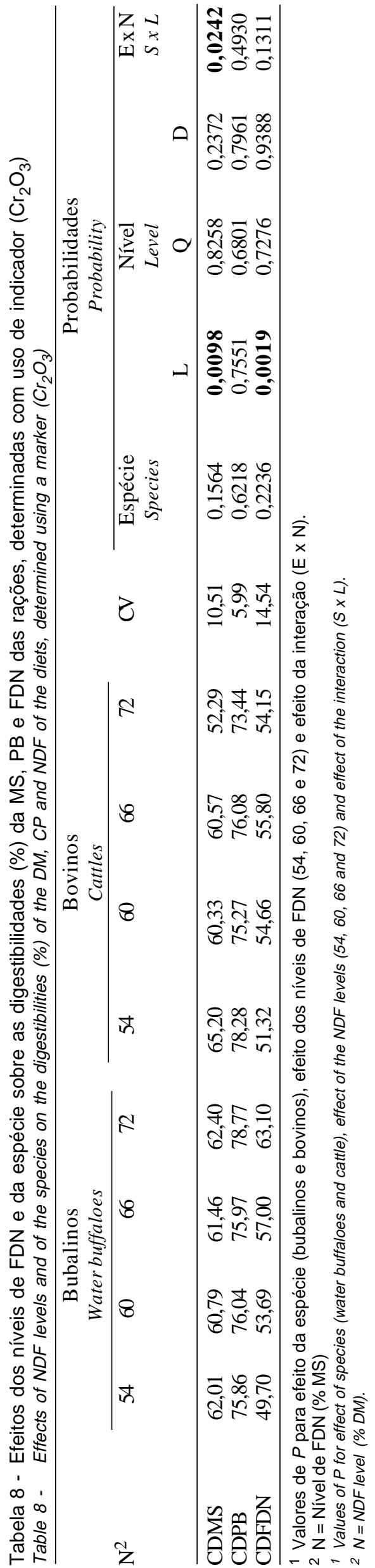

SOUZA et al.

\section{Conclusões}

Os bubalinos apresentaram maior degradabilidade efetiva da MS e PB do feno de coast-cross, milho em grãos e farelo de soja que os bovinos. Por outro lado, o degradabilidade efetiva da FDN do farelo de trigo foi maior para os bovinos.

Os bovinos apresentaram diminuição linear no coeficiente de digestibilidade da MS das rações, com aumento de níveis de FDN na dieta, porém não foi observado efeito nos bubalinos, indicando melhor digestibilidade dos carboidratos não-estruturais nos bubalinos, já que ambas espécies apresentaram semelhantes coeficientes de digestibilidade da FDN, com níveis crescentes de FDN na ração.

\section{Referências Bibliográficas}

BHATIA, S.K., PRADHAN, K., SINGH, R. et al. 1992. Effect of feeding wheat straw and oat on rumen microbial and enzymatic activities in cattle and buffalo. Ind. J. Anim. Sci., 62(4):364-368.

CHIMWANO, A.M., ØRSKOV, E.R., STEWART, C.S. 1976. Effect of dietary proportions of roughage and concentrate on rate of digestion of dried grass and cellulose in the rumen of sheep. Proc. Nutrition Society, 35:101A.

DEVENDRA, C. The utilization of nutrient, feeding systems and nutrient requirements of swamp buffaloes. In: SIMPOSIUM ON THE WATER BUFFALO, 1983, Tsukuba, Japan. Proceedings... s.n.t.,1983, 34p.

EZEQUIEL, J.M.B. Exigências de proteína e minerais de bovídeos:frações endógenas. Viçosa, MG: UFV, 1987. 131p. Tese (Doutorado em Zootecnia) - Universidade de Viçosa, 1987.

GARCIA, A.B. Digestão parcial e total de carboidratos em quatro diferentes grupos genéticos de novilhos. Viçosa, MG: UFV, 1982. 68p. Dissertação (Mestrado em Zootecnia) Universidade Federal de Viçosa, 1982.

GOMES, S.Z. Digestão parcial e total da proteína energia e consumo voluntário de matéria seca por diferentes grupos genéticos de bovídeos. Viçosa, MG: UFV, 1982. 106p. Tese (Doutorado em Zootecnia) - Universidade de Viçosa, 1982.

GONÇALVES, L.C. Digestibilidade, composição corporal, exigências nutricionais e características das carcaças de zebuínos, taurinos e bubalinos. Viçosa, MG: UFV, 1988. 238p. Tese (Doutorado em Zootecnia) - Universidade de Viçosa, 1988.

GONÇALVES, L.C., COELHO DA SILVA, J.F., ESTEVÃO, M.M. et al. 1991. Consumo e digestibilidade da matéria seca e da energia em zebuínos e taurinos, seus mestiços e bubalinos. R. Soc. Bras. Zootec., 20(4):384-395.

GRANER, C.A.F. Determinação do crômio pelo método colorimétrico da S-difenilcarbazida. Botucatu, SP: FCMB, 1972. 112p. Tese (Doutorado em Ciências) - Faculdade de Ciências Médicas e Biológicas, 1972.

GRANT, R.J., VAN SOEST, P.J., McDOWELL, R.E. et al. 1974. Intake, digestibility and metabolic loss of napier grass by cattle and bullaloes when fed wilted, chopped and whole. J. Anim. Sci., 39(2):423-434. 
Rev. bras. zootec.

HOPSON, J.D., JOHNSON, R.R., DEHORITY, B.A. 1963. Evaluation of the dracon technique as a method for measuring cellulose digestibility and the rate of forage digestion. J.Anim. Sci., 22:448-453.

HUNTINGTON, J. A., GIVENS, D. I. 1995. The in situ technique for studding the rumen degradation of feeds: a review of procedure. Nutrition Abstracts and Reviews (Series B), 65(2):63-93.

KENNEDY, D.W., BUNTING, L.D. 1992. Effects of starch or ruminal fermentation and detergent fiber digestion in lambs fed bermudagrass hay. An. Feed Sci. Tech., 36(1/2):91-100.

LORENZONI, W.R. Estudos sobre eficiências nutritivas e qualidade da carcaça de diversos grupos genéticos de bovídeos. Viçosa, MG: UFV, 1984. 51p. Dissertação (Mestrado em Zootecnia) - Universidade de Viçosa, 1984.

MERTENS, D.R. Análise da fibra e sua utilização na avaliação e formulação de rações. In: Anais do Simpósio Internacional de Ruminantes.REUNIÃO ANUAL DA SOCIEDADE BRASILEIRA DE ZOOTECNIA, 29, Lavras, 1992, Anais... Lavras, MG: SBZ, 1992.

MILLER, B.G., MUNTIFERING, R.B. 1985. Effect of forage on kinetics of forage fiber digestion in vivo. J. Dairy Sci., 68(1):40-44.

NOGUEIRA FILHO, J.C.M. Estudo da degradabilidade in situ e de protozoários ciliados com zebuínos da raça Nelore (Bos taurus indicus) e búfalos (Bubalus bubalis) submetidos a dietas com volumosos e concentrados. Pirassununga, SP: FZEA, 1995. 144p. Tese (Livre Docência) - Faculdade de Zootecnia e Engenharia de Alimentos/Universidade de São Paulo, 1995.

ØRSKOV, E.R, DeB HOVELL, F.D., MOULD, F. 1980. Uso de la tecnica de la bolsa de nylon para la avaluacion de los alimentos. Prod. Anim. Trop., 5(3):213-233.

PIMENTEL GOMES, F. 1985. Curso de estatística experimental. Piracicaba, SP: ESALQ. 467p.

RAZDAN, M.N., SHARMA, D.D., BHARGAVA, P.K. et al. 1971. Utilization of urea and water metabolism by zebu cattle and buffaloes wider tropical conditions. J. Dairy Sci., 54(8):1200-1208.

RESENDE, F.D., QUEIROZ, A.C., FONTES, C.A.A. et al. Fibra em detergente neutro versus fibra em detergente ácido na formulação de dietas para ruminantes. 1995. R. Soc. Bras. Zootec., 24(3):342-350.

RODRIGUEZ, L.R.R., FONTES, C.A.A., JORGE, A.M. et al. 1996. Consumo de rações contendo quatro níveis de concentrado por bovinos holandeses e nelores e por bubalinos. $R$. Soc. Bras. Zootec., 25(3):568-581.
SAS Institute Inc. SAS User's guide: statistics. Ver. 5 ed., SAS Inst., Cary, NC, 1985.

SEBASTIAN, L., MUDGAL, V.D., NAIR, P.G. 1970. Comparative efficiency of milk production by sahiwal cattle and murrah buffalo. J. Anim. Sci., 30(2):253-283.

SHULTZ, E., SHULTZ, T.A., GARMENDIA, J. et al. 1977. Comparicion entre bovinos y bufalos alimentados com forrage tropical en três estados vegetativos. 2. Processos fermentativos en el rumen. Agric. Trop., 27(6):621-627.

SIDDONS, R.C., PARADINE, J. 1981. Effects of diets on protein degrading activity in the sheep rumen. J. Sci. Food Agric., 32:973-981.

SILVA, D.J. 1981. Análise de alimentos - métodos químicos e biológicos. Viçosa, Imprensa Universitária. 166p.

SILVA, J.F.C., CAMPOS, J., CONRAD, J.H. 1968. Uso do óxido crômio na determinação da digestibilidade. Experientiae, $8(1): 1-10$.

VALADARES FILHO, S.C. Digestão total e parcial da matéria seca e carboidratos em bovinos e bubalinos. Viçosa, MG: UFV, 1985. 148p. Tese (Doutorado em Zootecnia) - Universidade de Viçosa, 1985.

VALADARES FILHO, S.C., COELHO DA SILVA, J.F., LEÃO, M.I. et al. 1990. Digestibilidade in vitro e alguns parâmetros de fermentação ruminal medidos em novilhos holandeses, Nelores e búfalos mestiços alimentados com ração purificada. R. Soc. Bras. Zootec., 19(5):441-449.

VALADARES FILHO, S.C. Utilização da técnica in situ para avaliação dos alimentos. In: SIMPÓSIO INTERNACIONAL DE PRODUÇÃO DE RUMINANTES. REUNIÃO ANUAL DA SOCIEDADE BRASILEIRA DE ZOOTECNIA, 31, 1994, Maringá. Anais...Maringá, 1994, p.95-118.

VIRK, A.S., MALIK, N.S., CHOPRA, A.K. 1981. Performance of growing and lactating buffaloes on diets containing dried brewer's grain. Indian J. Anim. Sci., 5(1):17-25.

Recebido em: 13/10/99

Aceito em: 02/04/00 